\title{
The Effects of YouTube in Multimedia Instruction for Vocabulary Learning: Perceptions of EFL Students and Teachers
}

\author{
Raniah Kabooha ${ }^{1} \&$ Tariq Elyas ${ }^{2}$ \\ ${ }^{1}$ English Language Institute, King Abdul Aziz University, Jeddah , Kingdom of Saudi Arabia \\ ${ }^{2}$ Faculty of Arts and Humanities, European Languages Department, King Abdul Aziz University, Jeddah, \\ Kingdom of Saudi Arabia \\ Correspondence: Raniah Kabooha, English Language Institute, King Abdul Aziz University, Jeddah 22431, \\ Kingdom of Saudi Arabia. E-mail: rkabouha@kau.edu.sa
}

Received: December 7, 2017 Accepted: January 10, 2018 Online Published: January 11, 2018

doi: 10.5539/elt.v11n2p72 URL: http://doi.org/10.5539/elt.v11n2p72

\begin{abstract}
The present study sought to examine the improvement in vocabulary comprehension and retention of Saudi English as foreign language female students at King Abdul Aziz University as a result of integrating YouTube in their reading classes. The study also investigated the perceptions of both students as well as teachers towards the inclusion of YouTube on the development of vocabulary. One hundred female intermediate level students aged between 18-20 years old participated in the study. Students were divided into two groups: an experimental group who watched YouTube during the reading activities and a control group who was not exposed to the videos. Data were collected using pre-tests and post-tests in addition to questionnaires. The findings of the study reveal that the group who viewed the YouTube clips outperformed the group who was not exposed to YouTube videos in the posttest. The results clearly show that YouTube provided statistically significant effects on the students' vocabulary acquisition. The findings of the study indicate that the participants positively viewed the use of YouTube in their lessons. The findings also revealed significant improvement in the students' vocabulary achievement. The implications of the findings are discussed within the context of foreign language learning and teaching.
\end{abstract}

Keywords: YouTube, EFL, vocabulary teaching and learning, multimedia instruction, technology and language learning

\section{Introduction}

\subsection{Background}

Acquiring a second/ foreign language requires a number of competencies and constituents (Mansourzadeh, 2014). Vocabulary is one of these essential components in language learning (Kabooha \& Elyas, 2015). The crux of the matter is that without enough vocabulary, the English language learners cannot comprehend written texts; nor can they convey messages to others. The language learners cannot communicate effectively without vocabulary. According to Harmer (2001), vocabulary is the core of language; he further suggests that if grammar is considered the skeleton of language, then vocabulary is the flesh (Harmer, 2001, p. 246). Thornburry (2002) believes that if learners spend a great amount of time studying grammar, they will not be able to make much progress in their language learning, but learning more vocabulary will help them make more improvement in language learning. However, vocabulary teaching and learning have been considered a challenge for EFL teachers as well as learners because there has been minimal attention given to vocabulary teaching in the EFL classrooms over the years (Shoaib, 2014). Thus, the need for developing effective pedagogical techniques for L2 vocabulary teaching is one of the main concerns among many second language acquisition researchers and scholars.

Research on vocabulary and its role in English as a foreign language teaching and learning are centred on various strategies used by students to learn vocabulary (e.g., Schmitt, 1997; Oxford, 1990; Fan, 2003; Seddigh \& Shokrpur, 2012). In addition, there are other studies that investigated the use of technology to help students acquire targeted vocabulary (e.g., Bagheri, Roohani \& Ansari, 2012; Dalton \& Grisham, 2011; Kilickaya \& Krajka, 2010). The social media in recent years has been considered an effective tool to supplement the 
traditional teaching methods (Buzzetto-More, 2012). One of these technologies that teachers use is YouTube. Bonk (2008) argues that it is the tool of the culture and that instructors in all educational institutions need to begin to use it in their classes. Because YouTube is to a certain extent a new phenomenon, scholars and researchers in second language acquisition are concerned about its effectiveness in the language classrooms. YouTube supplies limitless opportunities to maximize learning for language students and "has the potential to anchor instruction in such rich learning contexts" (Bonk, 2008, p. 10).

The combination of the aural input with the visual images on YouTube has encouraged many educators to adopt it as a teaching tool in their classes (Kuo, 2009). The language learners can receive the utterance and visual stimuli simultaneously, which can enhance their language learning skills as well as their vocabulary comprehension. In addition, using videos to improve students' vocabulary recognition and comprehension provides language learners the exposure to authentic content and context, thus the learners can improve their language skills (Ktoridou, Yiangou, \& Zarpetea, 2002). Research on the application of YouTube in language classrooms has shown significant findings that encourage its use with systematic planning. However, studies on the effectiveness of YouTube in vocabulary teaching and learning are very limited. Therefore, the primary aim of the current study is to investigate the impact of YouTube on EFL students' vocabulary retention and comprehension. This will add to the existing knowledge base of integration YouTube technology in language classroom. The study sought to answer the following questions:

(1) To what extent does the use of YouTube in EFL classes improve the vocabulary comprehension and retention of students?

(2) How do the students view the use of YouTube in their class as a tool to enhance their vocabulary learning?

(3) How do the teachers perceive the use of YouTube as a tool to improve students' vocabulary learning?

\section{Literature Review}

\subsection{The Cognitive Theory of Multimedia Learning (CTML)}

Richard Mayer (2005) proposed the Multimedia Learning Theory which maintains that multimedia instruction enhances the functionality of the individual's brain. The assertion of the theory is that effective learning involves the use of both images and words. Multimedia is defined as the utilization of text and pictures or visuals and sounds or any combination of visual and auditory cues (Mayer, 2005). According to the theory, one of the main aims of teaching using multimedia is to encourage the learner to build a coherent mental representation from the presented material. The learner has to make sense of the presented material as an active participant, which leads to the construction of new knowledge (Mayer, 2003). Mayer (2010) argues that meaningful learning from words and pictures happens when the learner engages in five cognitive processes. These include selecting relevant words for processing in verbal working memory as well as relevant images for processing in visual working memory, organizing selected words into a verbal model as well as selected images into a pictorial model and finally integrating the verbal and pictorial representations with each other and with prior knowledge. To connect the Multimedia theory to the present study, multimedia helps in creating deeper meaningful learning as opposed to rote memorization, thus, the integrating of YouTube in EFL classes can enhance the language learning experience and improve students' vocabulary knowledge.

\subsection{The Use of Multimedia in Vocabulary Acquisition}

Many second language acquisition researchers studied the effect of multimedia instruction on vocabulary development. They have found that the use of supplementary prompts such as pictures and videos enhances language learning. Chun \& Plass (1996) argued that supporting vocabulary learning with pictorial and verbal cues can help increase the recall and retention of the lexical items. Al-Seghayer (2001) conducted a study that investigated the impact of different modes of multimedia: "the printed text definition alone, printed text definition coupled with still pictures, and printed text definition coupled with video clips" (Al-Seghayer, 2001, p.202). The findings of the study indicated that the use of video clips with a text definition is more productive in the acquisition of new English vocabulary than the use of picture with a text definition. Students in the study were able to learn and remember more vocabulary when videos were used than when pictures were given. The application of different supporting cues can provide meaningful learning experience.

\subsection{Using Videos/YouTube in Language Learning and Teaching}

YouTube technology can be considered as a valuable learning tool. A growing body of research has shown significant findings that encourage the integration of YouTube video clips in education. Mayer (2001) stresses that the use of videos is greatly effective especially for introductory courses as it can facilitate difficult concepts, and attract the attention of weak students as well as visual/ special students. YouTube is a multidimensional 
resource that offers videos in all fields of knowledge that can be accessed effortlessly. In addition, videos on YouTube are limited in length; this makes them suitable for the tight classroom's time. Studies have also examined the effect of YouTube on autonomous learning (Hafner \& Miller, 2011). Researchers also found that the use of YouTube can improve students' involvement and participation in the classroom and learning strategies (Callow \& Zammit, 2012). Berk (2009) argues that the verbal and visual elements provided by the online video clips match the idiosyncrasies of the Net Generation of learners and address their different learning styles.

While the literature is varied in terms of the significance of integrating dynamic videos and/or YouTube in education in general and in the language classroom in particular, there has not been any research conducted to study the effects of using YouTube in Saudi EFL classrooms to enhance EFL students' vocabulary recognition and retention. The current study attempts to fill this gap in the literature.

\section{Methodology}

\subsection{Participants}

A sample from the population was selected based on convenient sampling method. The participants in the study consisted of one hundred Saudi female students studying English as a Foreign Language in their preparatory year at King Abdul Aziz University. The students' ages ranged between 18 and 20 years old. For the purpose of the study, four classrooms with 25 students in each were involved. The students were all at pre-intermediate level of proficiency in the English language. The study also included four female non-native speakers of English teachers.

\subsection{Research Design}

A pre-tests- post-test and control group design was utilized in the study. The students as well as teachers were required to complete a questionnaire. The students were randomly assigned into two groups: the experimental group who watched YouTube during their reading class and the control group who were not exposed to YouTube. Both groups did the pre-tests-post-tests, a week before and after the treatment. The main aim of the pre-tests was to assess students' knowledge of the new vocabulary while the post-tests aimed at examining the learners' recognition of the target vocabulary. The study was carried out over one module (seven weeks) according to the educational system of the context of the current study.

\subsection{Methods of Data Collection}

The study used the results of pre-tests and post-tests along with two questionnaires to answer the research questions. The VKS test, which was developed by Wesche and Paribbakht (1996), was utilized in the study as the pre-test and post-test measure that aimed at assessing the learners' knowledge of the target vocabulary. The study also utilized a questionnaire to assess the students' perception of using YouTube videos in their classes. The second questionnaire was used to record the teachers' perception of using YouTube videos in their classes. The questionnaires were only administered to the experimental group.

\subsection{The Administration}

In the current study, the researcher followed the steps suggested by Berk (2009) for using video clips in teaching. The participants in the study were initially informed about the fact that their participation in the study was voluntary. When participants had given consent to participate, they were required to take the pre-test Vocabulary Knowledge Scale to determine their background knowledge of the target words. The teachers were given explicit instructions on how to conduct the activity for the duration of the study. They were provided with the instructions and materials to teach the students.

A week after the pre-test was administered, the teachers introduced the topic and the new vocabulary to the students using a PowerPoint presentation provided to them by the researcher. The presentation slides illustrated the target vocabulary with some pictures to help facilitate the students' understanding of the new words. This activity was the same for both the experimental and control groups. Once this was done, students in the experimental group classes were divided into groups and were told that they were going to watch a two -minute YouTube video and the topic of the video was briefly explained to them. Before they watched the video, the teachers were asked to write one or two general questions on the board related to the video, such as "what is the message of the clip?", "what is your opinion of what the people are doing in this video?" Once they finished viewing the video, they were given a few minutes to discuss their answers with their group members. After that, one representative in each group was asked to provide the answers. The teachers were asked to encourage the students to use the new vocabulary they had learned. After this was completed, the teachers were asked to play the video again and this time they were asked to try to draw the students' attention to the new vocabulary, their use, $\&$ pronunciation. They were asked to pause and replay the clip to emphasize the new vocabulary. As a 
follow up activity, students in groups were required to prepare a role-play in which they were encouraged to use the newly learned vocabulary. A week after the treatment, a post-test (VKS) was administered to the students in both groups to determine how much they were able to retain of the target vocabulary. The second vocabulary activity was carried out following exactly the same steps as in the first session.

\section{Results}

\subsection{Comparing Pre-test results between the Experimental and Control Groups}

In order to find out if there were any significant differences between the pre-test scores of the students in the experimental group and the control group, the researcher conducted an independent sample t-test. This test was carried out to establish that the sample in both the experimental group and the control group were similar in their proficiency of English and their ability to recognize and comprehend the targeted words. A significant difference in the result would suggest that the study was inconclusive. The following table gives the results:

Table 1. Pre-test independent sample t-test

\begin{tabular}{llllll}
\hline Group & $\mathrm{N}$ & $\mathrm{M}$ & $\mathrm{SD}$ & $\mathrm{T}$ & $\mathrm{p}$ \\
\hline Experimental & 75 & 22.6 & 7.5 & -.495 & 0.622 \\
Control & 25 & 23.4 & 8.3 & & \\
\hline
\end{tabular}

The results reveal that there was no significant difference $(t(98)=-.495, p>0.05)$ between the pre-test scores of the experimental group $(\mathrm{M}=22.6, \mathrm{SD}=7.5)$ and the pre-test scores of the control group $(\mathrm{M}=23.4, \mathrm{SD}=8.3)$. This shows that both groups were at the same level of proficiency before the module began thereby indicating that the sample of the population chosen for the study was fair.

\subsection{Comparing Post-test results between the Experimental and Control Groups}

An independent sample t-test was conducted to compare the post-test scores of the experimental group and the control group. The results reveal that the post-test scores of the students in the experimental group $(\mathrm{M}=46.5$, $\mathrm{SD}=8.6)$ were significantly higher $(t(98)=7.515, p<0.05)$ when compared to the scores of the students in the control group $(\mathrm{M}=31.3, \mathrm{SD}=9.2)$. This indicates that the integration of YouTube had a powerful effect on the students' ability to recognize and understand the target vocabulary. The results are given in Table 2:

Table 2. Post-test independent sample t-test

\begin{tabular}{llllll}
\hline Group & $\mathrm{N}$ & $\mathrm{M}$ & $\mathrm{SD}$ & $\mathrm{T}$ & $\mathrm{p}$ \\
\hline Experimental & 75 & 46.5 & 8.6 & 7.515 & 0.000 \\
Control & 25 & 31.3 & 9.2 & & \\
\hline
\end{tabular}

\subsection{Pre-test versus Post-test Results of the Vocabulary Knowledge Scale (VKS)}

In order to find out if the students made significant improvement in their vocabulary recognition skills as a result of their learning for the duration of one module ( seven weeks), a paired sample t-test was conducted comparing means of the Vocabulary Knowledge Scale (VKS) test carried out before the lessons were taught and those conducted after. The results show that there was a significant improvement $(t(99)=-17.021, p<0.05)$ in vocabulary recognition and understanding among the students when comparing the scores of the students on the tests carried out before $(\mathrm{M}=22.8, \mathrm{SD}=7.7)$ and after $(\mathrm{M}=42.7, \mathrm{SD}=10.9)$ the lessons were conducted. This suggests that the current established lesson plan results in the students being able to recognize and understand the target vocabulary. 


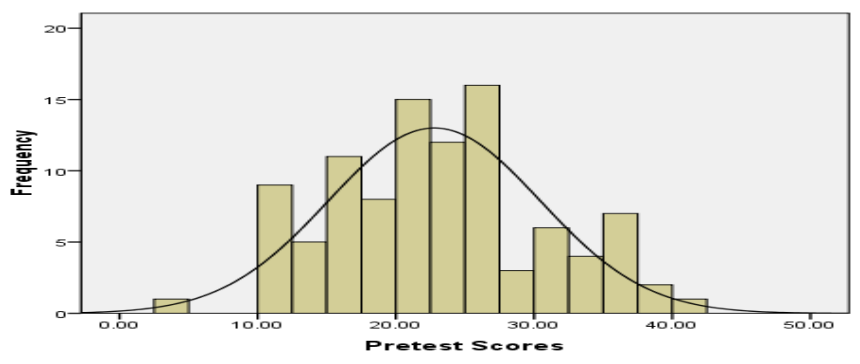

Figure 1. Distribution of pre-test scores

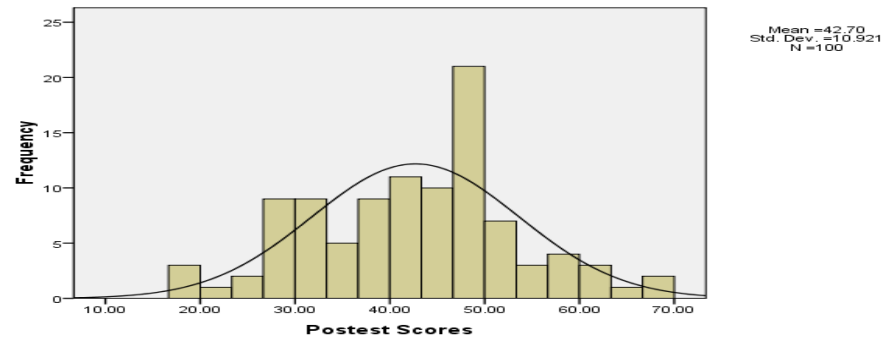

Figure 2. Distribution of post-test scores

Table 3. General paired sample t-test to see if significant improvement has occurred in vocabulary recognition and understanding

\begin{tabular}{llllll}
\hline Scores & $\mathrm{N}$ & $\mathrm{M}$ & $\mathrm{SD}$ & $\mathrm{T}$ & $\mathrm{p}$ \\
\hline Pre-Test & 100 & 22.8 & 7.7 & -17.021 & .00 \\
Post-Test & 100 & 42.7 & 10.9 & & \\
\hline
\end{tabular}

\subsection{Students'Perceptions of Using YouTube in Learning English Vocabulary Questionnaire}

It can be seen that, generally, the use of YouTube in classroom activities were considered to be useful by the students. The first eight questions focused on the students' perception of how useful YouTube was in helping them acquire new vocabulary. When they were asked about if using YouTube enriched their vocabulary knowledge, $96 \%$ of the students agreed to the statement whereas only four percent of the students were undecided on the stand. When asked if using YouTube videos to enhance vocabulary knowledge can improve the quality of the assignments that they submit, $83 \%$ of the students agreed that YouTube videos helped them write better assignments whereas five percent of the students disagreed. Twelve percent of the students remained undecided. When asked if YouTube videos made it easier to learn English vocabulary, $89 \%$ of the students concurred while the rest of the students were undecided. On the question of whether YouTube helped in learning correct pronunciation, $81 \%$ of the students agreed while seven percent of the students disagreed and $12 \%$ of the students remained undecided.

The second section consisted of four items that dealt with the students' perception of how easy it was to use YouTube videos in learning vocabulary in the English language. The first item asked if the students found it easy to use YouTube videos in learning vocabulary for which $85 \%$ of the students agreed while only three percent of the students disagreed with the rest of the students marking undecided. The majority of the students considered it easy to access YouTube and the rest of the students were undecided. Seventy five percent of the students found that it is easy to use YouTube videos to learn the English language vocabulary. Twenty three percent of the students were undecided on that item and the rest of the students disagreed. When the students were asked the first question with specific emphasis on the English language, only $76 \%$ of the students agreed with $21 \%$ of the students remaining undecided.

The last section also had four items which were to find out the students' attitude towards the use of YouTube videos in language learning. The majority of the students considered YouTube to be an attractive learning tool that can help them learn the English vocabulary, but three percent of the students disagreed. About $24 \%$ of the 
students did not answer either way. Five percent of the students did not find it attractive while $24 \%$ of the students did not give an answer either way. When asked if they enjoyed using YouTube videos to learn English vocabulary $77 \%$ of the students agreed while three percent of the students disagreed and $20 \%$ of the students remained undecided. The final question asked if YouTube enhanced their confidence in using the English Language to which $69 \%$ of the students agreed, eight percent of the students disagreed and $23 \%$ of the students failed to take a stand. Table 4 gives a summary of their responses:

Table 4. Frequency of responses for students' perception questionnaire

\begin{tabular}{lcccccc}
\hline & Strongly Disagree & Disagree & Undecided & Agree & Strongly Agree & Mean of Scores \\
\hline Perceived Usefulness 1 & 0 & 0 & 3 & 31 & 41 & 4.5 \\
Perceived Usefulness 2 & 1 & 3 & 9 & 32 & 30 & 4.2 \\
Perceived Usefulness 3 & 0 & 0 & 8 & 36 & 31 & 4.3 \\
Perceived Usefulness 4 & 2 & 3 & 9 & 30 & 31 & 4.1 \\
Perceived Usefulness 5 & 1 & 2 & 3 & 38 & 31 & 4.3 \\
Perceived Usefulness 6 & 1 & 2 & 5 & 33 & 34 & 4.3 \\
Perceived Usefulness 7 & 1 & 3 & 18 & 22 & 31 & 4.1 \\
Perceived Usefulness 8 & 2 & 7 & 30 & 19 & 17 & 3.6 \\
Perceived Ease of Use 1 & 0 & 2 & 9 & 44 & 20 & 4.1 \\
Perceived Ease of Use 2 & 0 & 0 & 8 & 30 & 37 & 4.4 \\
Perceived Ease of Use 3 & 0 & 2 & 17 & 31 & 25 & 4.1 \\
Perceived Ease of Use 4 & 0 & 2 & 16 & 27 & 30 & 4.2 \\
Attitude 1 & 0 & 2 & 18 & 31 & 24 & 4.1 \\
Attitude 2 & 1 & 3 & 18 & 26 & 27 & 4.1 \\
Attitude 3 & 0 & 2 & 15 & 29 & 29 & 4.2 \\
Attitude 4 & 2 & 4 & 17 & 26 & 26 & 4.0 \\
\hline
\end{tabular}

\subsection{Perceptions of the Teachers towards the Use of YouTube Videos in Teaching English Vocabulary}

The questionnaire for the teachers focused on how beneficial using YouTube was in teaching English vocabulary to the students effectively. The results reveal that generally the teachers perceived using YouTube videos to be beneficial in teaching vocabulary of the English language to EFL students. The questionnaire consisted of 12 questions focusing on the benefits of using YouTube Technology in the classrooms for the purpose of teaching vocabulary to the students. When asked if YouTube can motivate the students to learn English, two of the teachers strongly agreed and the third just agreed. To the question of whether or not YouTube provides the students with a variety of opportunities for learning English vocabulary, all the teachers strongly agreed. When asked if YouTube can deliver the meaning of the target words effectively, all teachers strongly agreed. Two of the teachers agreed and one strongly agreed to the question of whether YouTube offers authentic materials for teaching English vocabulary. When asked if teachers required special training to use YouTube effectively in the classroom, all the teachers strongly agreed.

To the point that using YouTube to teach English vocabulary maximises students' involvement, all teachers in the experimental group strongly agreed. When asked if the EFL teachers should be encouraged to employ YouTube video clips in teaching English vocabulary, two of the teachers in the experimental group strongly agreed while the third teacher merely agreed. To the question whether YouTube vocabulary activities can improve students' learning interest, all the teachers strongly agreed. When asked if students can broaden their vocabulary knowledge through YouTube related vocabulary activities, two of the teachers strongly agreed with the third 
teacher also agreeing to the statement. YouTube video watching is a useful learning material for EFL learners received strong agreement from all the teachers. For the question, using YouTube for teaching English vocabulary can improve the vocabulary retention of the students also received strong agreement from all the teachers. YouTube provides an attractive learning environment for the students also got strong agreement from all the participants.

\section{Discussion}

From the findings of the current study, it can be seen that both students as well as teachers believe YouTube technology to be an effective tool that can help the students understand and comprehend the English language or in this case, the target English vocabulary better. The majority of the students found YouTube to be helpful in improving their comprehension of the English vocabulary. In addition, the significant difference in the scores of the pre-tests and post-tests shows that integrating YouTube has improved the students' ability to recognize and comprehend the target vocabulary better. The cognitive Theory of Multimedia Learning theory gives a good explanation as to why videos help the students to learn better. The theory suggests that presenting information in video format caters to both the visual as well as auditory senses and that provides a more effective method of teaching than just through either of those senses alone (Mayer, 2001).

The majority of the students in the study strongly agreed that the use YouTube in their classrooms for learning new vocabulary provided an attractive and interesting learning environment and that it motivated them to lean faster and better. Terantino (2011) contends that YouTube offers learners with access to language and culture-based videos while being fun and interesting. Additionally, it also gives the students an avenue to get information and instruction from all over the world thus providing them 'an opportunity to engage meaningfully in the target language' (Terantino 2011, p. 11). The students of the current study agreed that integrating YouTube videos as part of the classroom activities motivates them to study as well as raises their interest because it is attractive $73 \%$ and enjoyable $77 \%$. All the teachers also support this strongly. This is one of the top reasons for using YouTube videos in the classroom according to several studies including that of Alimemaj (2010) who believes that YouTube provides motivation to both intrinsically and extrinsically motivated students because it is a technology that deals with the present popular culture. Another study conducted by Alwehaibi (2013) shows that the enjoyable and entertaining atmosphere that is brought on by using videos in classrooms result in the students being motivated to learn.

The results show that the students of the current study found YouTube to be helpful in learning as well as remembering new vocabulary $71 \%$. The teachers also thought that YouTube improved students' ability to retain and comprehend the target vocabulary. This has been supported by several studies including that of Balcikanli (2011) who believes that as YouTube provides several videos on any given subject, the students are able to retain the words that they learn in their memory without having to get bored. All the teachers in the experimental group strongly agreed that the integration of YouTube in their classrooms increased students' involvement and engagement in the activities. Koksal (2004) believes that integrating video clips in to the classroom saves time because it usually helps to focus the students' attention and at the same time, get them involved in what is being conveyed by the teacher. The teachers of the current study all agreed that using YouTube videos in the classroom increased students' engagement in the teaching and learning process. Ghasemi, Hashemi and Bardine (2011) go as far as to say, that people in general, and students in particular actually respond to video formats than others, which in turn will lead the students to get actively involved in their learning process. Kelsen's (2009) ideas that introducing popular culture into the classroom can motivate the students is another way of looking at how YouTube can get students involved in the classroom. Kabooha (2016) also found that the use of short video clips in EFL classrooms to be significantly valuable as it results in the students being highly motivated and interactive in the various activities throughout the learning process. Teachers of the current study have agreed on the point that YouTube videos provide authentic language materials that will help students learn the English language. This is supported with the findings of numerous other studies which suggest authenticity as an integral benefit of YouTube videos. Alimemaj (2010) claims authenticity as a key feature of YouTube in addition to student motivation.

\section{Limitations}

There are some limitations to the current study. The population in the study was limited to female EFL students. The findings would have been more generalizable if the experiment was conducted on a mixed gender population. Additionally, all the students in the study were at the pre-intermediate level of proficiency. Another limitation to the study was the time constraint. The study was carried out over a short time frame. Thereby, the experiment duration should be considered and a longer period could be applied. 


\section{Conclusion}

The findings of the study suggest that EFL teachers should be encouraged to use YouTube in their classrooms. However, they need to be selective about the videos they decide to use in their classrooms in order to achieve maximum effectiveness regarding the improvement of students' ability to learn and retain any part of the language they are trying to teach (Fisher \& Frey, 2011). YouTube videos selected for the use in language classrooms should be based on certain criteria including proficiency level of the students, their cultural context, and the lesson's objectives. Therefore, teachers can make full use of the pedagogical implications of using YouTube videos in the classroom. For this purpose, the teachers who participated in the study unanimously agreed that they should be trained to effectively use YouTube in their classes in order to present the most useful lesson to the students on the target content. It can be seen that the students and the teachers find it very beneficial in vocabulary development. The findings of the study indicate that the integration of YouTube has a powerful effect on the vocabulary recognition, comprehension and retention of the target vocabulary. The current study should be taken as a foundation for other studies that need to be conducted for further validation and referencing. The significance of the results of the current study mandates future studies to be conducted on a mixed gender population on a larger scale. Future studies should also consider using a collection of English language institutions instead of just one institution like the current study.

\section{References}

Adams, D., Nelson, R., \& Todd, P. (1992). Perceived usefulness, ease of use, and usage of information technology: A replication. MIS Quarterly, 16, 227-247. https://doi.org/10.2307/249577

Ajzen, I., \& Fishbein, M. (1980). Understanding attitudes and predicting social behaviour. New Jersey: Prentice-Hall.

Ajzen, I. (1985). From intentions to actions: A theory of planned behaviour. In A. Kuhl, \& J. Beckmann (Eds.), Action Control: from Cognition to Behaviour (pp. 11-39). New York: Springer Verlag. https://doi.org/10.1007/978-3-642-69746-3_2

Akbulut, Y. (2007). Effects of multimedia annotations on incidental vocabulary learning and reading comprehension of advanced learners of English as a foreign language. Instructional Science, 35, 499-517. https://doi.org/10.1007/s11251-007-9016-7

Alimemaj, Z. (2010). YouTube, language learning and teaching techniques. The Magazine of Global English Speaking Higher Education, 2(3).

Al-Seghayer, K. (2001). The effect of multimedia annotation modes on L2 vocabulary acquisition: a comparative study. Language Learning and Technology, 5(1), 202-232.

Alwehaibi, H. (2013). The impact of using YouTube in EFL. Proceedings of the Clute International Academic Conference, Paris, France. Retrieved April 3, 2015, from www.cluteinstitute.com/index.html

Arthur, P. (1999). Why use video? A teacher's perspective. VSELT, 2(4), 373-398.

Bagheri, E., Roohani, A., \& Ansari, D. N. (2012). Methods of teaching on L2 vocabulary learning. Journal of Language Teaching and Research, 3(4), 744-752. https://doi.org/10.4304/j1tr.3.4.744-752

Balcikanli, C. (2011). Long live, YouTube: L2 stories about YouTube in language learning. Retrieved January 20, 2015, from,http://moodle.bracu.ac.bd/mod/resource/view.php?id=8

Bonk, C. (2008). YouTube anchors and enders: The use of shared online video content as a macro context for learning. Retrieved January 6, 2015, from http://www.publicationshare.com/SFX7EED.pdf

Brown, S. (2010). Popular films in the EFL classroom: Study of methodology. Procedia Social and Behavioral Sciences, 3, 45-54. https://doi.org/10.1016/j.sbspro.2010.07.011

Buzzetto-More, N. (2012). Social networking in undergraduate education. Interdisciplinary Journal of Information, Knowledge, and Management, 7, 63-90. https://doi.org/10.28945/1578

Callow, J., \& Zammit, K.(2012). 'Where lies your text?' (twelfth night act I, scene V): Engaging high school students from low socioeconomic backgrounds in reading multimodal texts. English in Australia, 47(2), 69-77.

Chun, D., \& Plass, J. (1996). Effects of multimedia annotations on vocabulary acquisition. The Modern Language Journal, 80(2), 183-198. https://doi.org/10.1111/j.1540-4781.1996.tb01159.x

Dalton, B., \& Grisham, D. (2011). eVoc strategies: 10 ways to use technology to build vocabulary. The Reading 
Teacher, 64(5), 306-317. https://doi.org/10.1598/RT.64.5.1

Davis, F. (1989). Perceived usefulness, perceived ease of use and user acceptance of information technology. Management Information Systems Quarterly, 13(3). https://doi.org/10.2307/249008

Davis, F., Bargozzi, R., \& Warshaw, P. (1989). User acceptance of computer technology: A comparison of two theoretical models. Management Science, 35, 982-1003. https://doi.org/10.1287/mnsc.35.8.982

Fan, M. (2003). Frequency of use, perceived usefulness, and actual usefulness of second language vocabulary strategies: A study of Hong Kong learners. Modern Language Journal, 87(2), 222-241. https://doi.org/10.1111/1540-4781.00187

Fisher, D., \& Frey, N. (2011). Using video and film in the classroom: Engaging the adolescent learner. Retrieved March 4, 2015, from http://www.reading.org/Libraries/Members-Only/Video_and_Film_FINAL.pdf

Ghasemi, B., Hashemi, M., \& Bardine, S. (2011). UTube and language learning. Procedia - Social and Behavioral Sciences, 28, 63-67. https://doi.org/10.1016/j.sbspro.2011.11.013

Hafner, C., \& Miller, L. (2011). Fostering learner autonomy in English for science: A collaborative digital video project in a technological learning environment. Language Learning and Technology, 15(3), 68-86.

Harmer, J. (2001). The practice of English language teaching. Longman: Pearson. Retrieved from http://www.scribd.com/Jeremy-Harmer-The-Practice-ofEnglish-Language-Teaching-New-Edition1/d/15602 107

Hendrickson, A., Massey, P., \& Cronan, T. (1993). On the test-retest reliability of perceived usefulness and perceived ease of use scale. MIS Quarterly, 17(2), 227-30. https://doi.org/10.2307/249803

Ismaili, M. (2013). The effectiveness of using movies in the EFL classroom -A study conducted at south east European university. Academic Journal of Interdisciplinary Studies, 2(4), 121-132. https://doi.org/10.5901/ajis.2012.v2n4p121

Kabooha, R., \& Elyas, T. (2015). The impacts of using YouTube videos on learning vocabulary in Saudi EFl classrooms. Proceedings of ICERI2015 Conference 16th-18th November 2015, Seville, Spain.

Kabooha, R. (2016). Using movies in EFL classrooms: A study conducted at the English Language Institute (ELI), King Abdul-Aziz University. English Language Teaching, 9(3), 248-257. https://doi.org/10.5539/elt.v9n3p248

Keene, M. (2006). Viewing video and DVD in the EFL classroom. Bunkyo Gakuin University Journal, 8(1), 217-234.

Kelsen, B. (2009). Teaching EFL to the iGeneration: A survey of using YouTube as supplementary material with college EFL students in Taiwan. CALL-EJ Online, 10(2).

Kilickaya, F., \& Krajka, J. (2010). Comparative usefulness of online and traditional vocabulary learning. The Turkish Online Journal of Educational Technology, 9(2), 55-64.

King, J. (2002). Using DVD feature films in the EFL classroom. Computer Assisted Language Learning, 15(5), 509-23. https://doi.org/10.1076/call.15.5.509.13468

Köksal, D. (2004). To kill the blackboard? Technology in language teaching. The Turkish Online Journal of Educational Technology-TOJET, 3(3), 62-72.

Lee, M., Cheung, C., \& Chen, Z. (2005). Acceptance of internet-based learning medium: The role of extrinsic and intrinsic motivation. Information \& Management, 42, 1095-1104. https://doi.org/10.1016/j.im.2003.10.007

Lewis, M. (1993). The lexical approach: The state of ELT and the way forward. England: Longman.

Li, C. (2012). Are they listening better? Supporting EFL college students' DVD video comprehension with advance organizers in a multimedia English course. Journal of College Teaching and Learning, 9(4), 1-13. https://doi.org/10.19030/tlc.v9i4.7298

Lin, L. (2010). A video-based CALL program for proficient and less-proficient L2 learners' comprehension ability, incidental vocabulary acquisition. Educational Media International, 47(3), 199-216. https://doi.org/10.1080/09523987.2010.518812

Mansourzadeh, N. (2014). A comparative study of teaching vocabulary through pictures and audio-visual aids. Journal of Elementary Education, 24(1), 47-59. 
Mayer, R. (2001). Cognitive principles of multimedia learning: The role of modality and contiguity. Journal of Education Psychology.

Mayer, R. (2003). Elements of a science of e-learning. Journal of Educational Computing Research, 29(3), 297-313. https://doi.org/10.2190/YJLG-09F9-XKAX-753D

Mayer, R. (2005). Cognitive theory of multimedia learning. In R. E. Mayer (Ed.), The Cambridge Handbook of Multimedia Learning. New York: Cambridge University Press. https://doi.org/10.1017/CBO9780511816819

Mayer, R. (2005). Introduction to multimedia learning. In R. E. Mayer (Ed.), The Cambridge Handbook of Multimedia Learning. New York: Cambridge University Press. https://doi.org/10.1017/CBO9780511816819.004

Mayer, R. (2009). Multimedia learning (2nd ed). New York: Cambridge University Press. https://doi.org/10.1017/CBO9780511811678

Mayer, R. E. (2010). Applying the science of learning to medical education. Medical Education, 44, 543-549. https://doi.org/10.1111/j.1365-2923.2010.03624.x

McKinnon, M. (2011). Teaching technologies: Teaching English using video. Retrieved January 1, 2015, from http://www.onestopenglish.com/support/methodology/teachingtechnologies/teaching-technologies-teaching -english-using-video/146527

Oxford, R. (1990). Language learning strategies: What every teacher should know. Boston: Newbury House.

Schmitt, N. (1997). Vocabulary learning strategies. In N. Schmitt, \& M. McCarthy (Eds.), Vocabulary: Description, acquisition and pedagogy. Cambridge: Cambridge University Press.

Seddigh, F., \& Shokrpur, N. (2012). Vocabulary learning strategies of medical students at Shiraz university of medical sciences. English Language Teaching, 5(2), 160-174. https://doi.org/10.5539/elt.v5n2p160

Stephens, C., Ascencio, R., Burgos, A., Diaz, T., Montenegro, J., \& Valenzuela, C. (2012). Film circles: Scaffolding speaking for EFL students. English Teaching Forum, 2, 14-21.

Teo, T., \& Van Schaik, P. (2009). Understanding technology acceptance among pre-service teachers: A structural equation modeling approach. The Asia-Pacific Education Researcher, 18(1), 47-66. https://doi.org/10.3860/taper.v18i1.1035

Teo, T. (2011). Factors influencing teachers' intention to use technology: Model development and test. Computers \& Education. https://doi.org/10.1016/j.compedu.2011.06.008

Terantino, J. (2011). YouTube for foreign languages: You have to see this video. Journal of Language \& Technology, 15(1).

Venkatesh, V., \& Davis, F. (2000). A theoretical extension of technology acceptance model: Four longitudinal field studies. Management Science, 46, 186-204. https://doi.org/10.1287/mnsc.46.2.186.11926

Venkatesh, V., Morris, M. G., Davis, G., \& Davis, F. (2003). User acceptance of information technology: Toward a unified view. MIS Quaterly, 27(3), 425-478. https://doi.org/10.2307/30036540

Wesche, M., \& Paribakht, T.(1996). Assessing second language vocabulary knowledge: Depth versus breadth. Canadian Modern Language Review, 53(1), 13-40.

Williams, R., \& Lutes, P. (n.d.). Using video in the ESL classroom. Retrieved April 6, 2015, from http://www.takamatsu-u.ac.jp/library/06_gakunaisyupan/kiyo/no48/001-013_williams.pdf

Xhemaili, M. (2013). The advantages of using films to enhance student's reading skills in the EFL classroom. Journal of Education and Practice, 4(13), 62-66.

Yousafzai, S., Foxall, G., \& Pallister, J. (2007). Technology acceptance: A meta analysis of the TAM. Journal of Modelling in Management, 2(3), 251-280. https://doi.org/10.1108/17465660710834453

\section{Copyrights}

Copyright for this article is retained by the author(s), with first publication rights granted to the journal.

This is an open-access article distributed under the terms and conditions of the Creative Commons Attribution license (http://creativecommons.org/licenses/by/4.0/). 